\title{
Implantação e consolidação de escritório de gerenciamento de projetos: um estudo de caso
}

\author{
Andréia Pereira Martins \\ Marcelo Ramos Martins \\ Marcia Moreira Martins Pereira \\ Vergílio Antonio Martins \\ Escola Politécnica da Universidade de São Paulo - Departamento de Engenharia Naval e Oceânica
}

\begin{abstract}
Resumo
Desde o final da década de 1990, quando teve início o processo de desregulamentação e privatização do setor de telecomunicações no Brasil, o crescimento desse setor tem sido significativo, com destaque especial nos serviços de telefonia celular. Dentre as estratégias de crescimento adotadas pelas quatro maiores empresas operadoras de telefonia celular no Brasil, está a utilização da aquisição de outras operadoras, que outrora operavam regionalmente, para chegar à posição de operação com cobertura nacional. Dos projetos de junção de empresas resulta como desafio a integração dos sistemas de TI, sendo que, para executá-los, as empresas têm buscado a utilização de técnicas modernas de gerenciamento de projetos, implantadas através dos Escritórios de Gerenciamento de Projetos (EGP). O presente trabalho apresenta as dificuldades encontradas no processo de implantação, consolidação e operação do EGP no contexto de junção de empresas operadoras de telefonia celular.
\end{abstract}

\section{Palavras-chave}

Escritório de Gerenciamento de Projetos (EGP), implantação do gerenciamento de projetos, junção de empresas, setor de telecomunicações, Tecnologia da Informação (TI).

\section{Project management office implementation and consolidation: a case study}

\begin{abstract}
The growth in telecommunications sector, mainly on mobile telephony, has been very significant since the end of 90 's due to the public policies adopted in Brazil. Among growth strategies, adopted for the four biggest mobile telephony companies in Brazil, there is the use of the joint ventures with other companies, that long ago worked regionally, in order to get the national operation status. As a result of joint venture process, there is the challenge of Technology Information Systems consolidation. Aiming to face these challenges, companies have been using project management practices implemented through the Project Management Offices (PMO). This paper presents the difficulties during the Project Management Office implementing and consolidation processes, in the context of mobile telephony companies' joint ventures.
\end{abstract}

\section{Key words}

Project Management Office (PMO), project management implementation, companies joint ventures, telecommunications sector, Information Technology (IT). 


\section{INTRODUĈ̣̃O}

Seguindo uma tendência mundial, o crescimento do setor de telecomunicações no Brasil tem sido significativo nos últimos anos, com destaque especial aos serviços de telefonia celular. Esse crescimento vem ocorrendo desde o final da década de 1990, quando teve início o processo de desregulamentação e privatização do setor. Entre 1994 e 2004, o número de terminais celulares passou de 755 mil para quase 68 milhões, conforme apontado na Figura 1. Em 2004, o mercado consumidor de telefonia celular estava distribuído por sete operadoras, com quatro delas detendo aproximadamente $92 \%$ do mercado (TELECO, 2005). O crescimento da magnitude do setor de telecomunicações no Brasil só tem sido possível devido ao processo de inovação tecnológica e de políticas públicas adotadas no Brasil a partir de 1997 (CAMPANÁRIO et al., 2004).

$\mathrm{O}$ modelo de crescimento da telefonia celular tem entre seus pilares de sustentação a competição entre as empresas operadoras de telefonia. Para garantir o princípio de concorrência, o poder público, através da Agência Nacional de Telecomunicações (ANATEL), outorga licenças para mais de uma operadora em uma mesma área de cobertura geográfica. As operadoras de celular do Brasil, com exceção de alguns casos especiais, têm as suas áreas de prestação de serviço correspondentes às dez áreas definidas originalmente para o Serviço Móvel Celular (SMC) ou para as quatro regiões do Serviço Móvel Pessoal (SMP).
Em conseqüência dessa política pública, algumas regiões no Brasil contam com até quatro operadoras deste serviço numa mesma área de concessão.

Da situação original de composição de operadoras do modelo SMC para o atual SMP, houve uma redução no número de competidores regionais, através da consolidação de operadoras, para atender ao requisito de cobertura nacional. Dentre as estratégias de crescimento, as quatro maiores empresas utilizaram-se da aquisição de outras, que outrora operavam regionalmente, criadas no modelo SMC, para se chegar à posição de operação com cobertura nacional. Devido a esse processo, as empresas se depararam com a necessidade de integrar seus processos e sistemas herdados das operadoras originais. Dentre esses sistemas, estão os sistemas de Tecnologia de Informação (TI).

Os sistemas de TI exercem um papel fundamental para a sobrevivência dos negócios das empresas. Tal qual em qualquer outro segmento de negócio com intensa utilização de sistemas de TI, um dos maiores desafios nos projetos de junção de empresas é a integração dos processos corporativos e de negócio, utilizando a integração dos sistemas como principal ferramenta para operacionalizálos. Para vencer este desafio, as empresas têm tratado este processo de consolidação como um conjunto de projetos e programas (portfólio ${ }^{1}$ ) e, visando atingir o resultado esperado, têm buscado a utilização de técnicas modernas de gerenciamento de projetos. Como conseqüência da adoção dessas técnicas pelas equipes de desenvolvimento de projetos de TI, observa-se a implantação de

Figura 1: Crescimento de Aparelhos Celulares no Brasil.

\section{Crescimento de Aparelhos Celulares no Brasil}

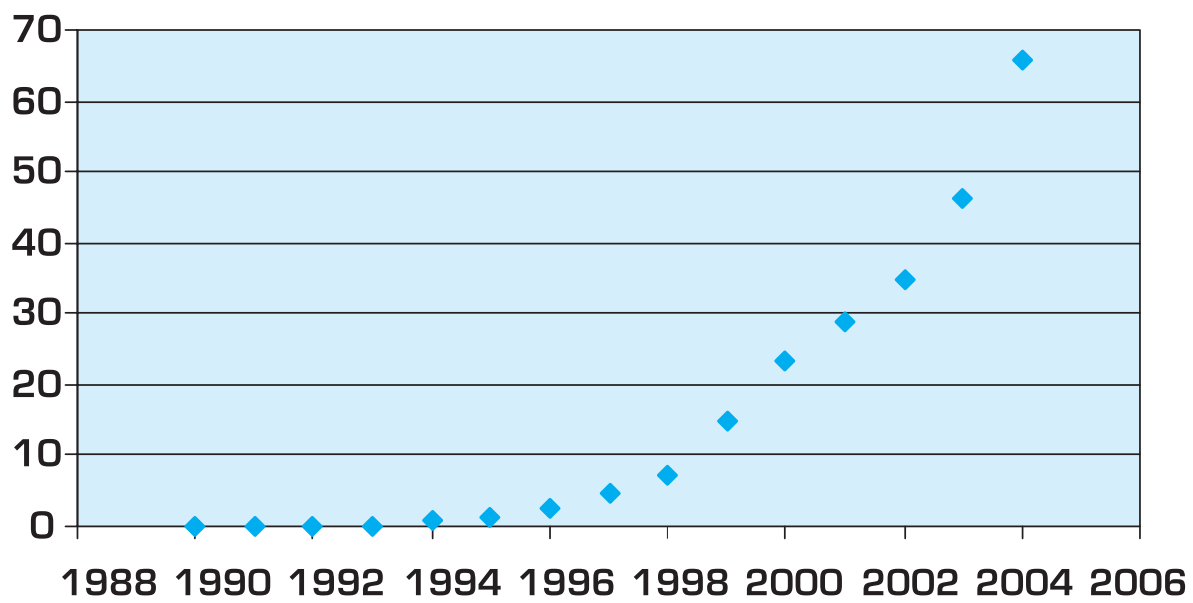

Fonte: ANATEL, citado por Teleco (2005). 
Escritórios de Gerenciamento de Projetos (EGP).

O EGP já é uma realidade em muitas empresas do setor de telecomunicações (BARCAUI, 2003), exercendo um papel subjacente no processo de crescimento das organizações, que é o de contribuir para a eficiência nos resultados dos seus projetos estratégicos.

O foco deste artigo é o estudo de fatores que influenciam os processos de implantação e consolidação de um EGP, tendo como base o estudo de caso em uma operadora de telefonia celular do Brasil e outros casos análogos, na forma de artigos, que também foram pesquisados. sua origem relacionada ao setor militar no período pósSegunda Guerra (WEBSTER ${ }^{2}$, apud CRAWFORD, 2002, p. 1). Desde então, tem sido cada vez mais utilizado, estando sua implantação em foco a partir de meados da década de 1990. Segundo Kerzner (2002), atualmente a implantação do gerenciamento de projetos constitui a gestão avançada de projetos. A empresa que pretende alcançar sucesso em gerenciamento de projetos deve desenvolver um processo de implantação bem sucedido, sendo fatores de sucesso, dentre outros: ter como base a cultura da organização, realizar treinamentos extensivos e contar com o comprometimento dos executivos, que devem reconhecer o valor que o gerenciamento formal de projetos acrescenta à empresa (KERZNER, 2002).

Assim, nos últimos anos, o foco do gerenciamento de projetos migrou da teoria para a sua

O trabalho iniciou com a revisão da literatura sobre gerenciamento de projetos, maturidade em gerenciamento de projetos e EGP. Também foram coletadas informações sobre outros casos já publicados. Em seguida, através de entrevistas, foram levantados dados sobre o processo de implantação do EGP e os projetos de integração dos sistemas de TI no caso em estudo. Uma vez apresentados os resultados, procurou-se elaborar a argumentação da análise, considerando-se as teorias de gerenciamento de projetos.

\section{REVISÃO BIBLIOGRÁFICA}

Os itens a seguir resumem a pesquisa bibliográfica realizada no presente estudo. Inicialmente são apresentados, em caráter introdutório, o conceito de gerenciamento de projetos, um breve histórico de sua origem e a evolução de sua utilização, atingindo diferentes indústrias. Em seguida, como fundamento para o item subseqüente, discorre-se sobre o EGP, suas atribuições e classificações. Finalmente, apresentam-se as recomendações encontradas na literatura no que concerne à implantação do EGP, foco deste trabalho acadêmico.

\section{Gerenciamento de Projetos}

Segundo o PMI ${ }^{\circledR}$ - Project Management Institute, associação americana não-lucrativa de profissionais de gerenciamento de projetos, essa disciplina busca atender os requisitos dos projetos através da aplicação de conhecimentos, competências, ferramentas e técnicas de gerenciamento de projetos (PROJECT MANAGEMENT INSTITUTE, 2000).

Embora gerenciar projetos seja uma prática muito antiga, o gerenciamento de projetos enquanto disciplina tem implantação, outras organizações passaram a utilizá-lo e surgiu o conceito de maturidade em gerenciamento de projetos. De acordo com Kerzner (2002), a maturidade em gerenciamento de projetos é o desenvolvimento de processos e sistemas repetitivos, de modo a aumentar a probabilidade de sucesso dos projetos submetidos a estes processos e sistemas.

Diversas são as razões pelas quais as organizações decidem pela implementação das práticas ou pela melhoria do nível de maturidade em gerenciamento de projetos. As forças que comumente motivam as empresas na busca pela maturidade em gestão de projetos são: os projetos estratégicos, as expectativas dos clientes, o entendimento da gestão de projetos como diferencial competitivo, o maior comprometimento dos gerentes executivos, o desenvolvimento de novos produtos e a melhoria da eficiência e da eficácia, sendo que todas estas forças objetivam a sobrevivência da empresa (KERZNER, 2002). Também podem ser considerados como fatores motivadores os benefícios associados ao uso do gerenciamento de projetos, dentre os quais destacam-se, entre os citados por Kerzner (2003), as melhorias em relação a: eficiência, lucratividade, controle de mudanças de escopo, relacionamento com clientes, identificação de riscos, qualidade, distribuição de informações e competitividade.

Entre as indústrias que apresentam crescente utilização do gerenciamento de projetos, Crawford (2002) cita os segmentos de TI, de serviços de informação e de desenvolvimento de novos produtos, que buscam obter, através do gerenciamento, benefícios específicos, a saber: a redução de custos, a diminuição do ciclo de vida para lançamento de novos produtos e a melhoria na qualidade dos produtos entregues. Também progrediram nesta disciplina os setores 
bancário, farmacêutico, de telecomunicações, de petróleo e de gás. Segundo Kerzner (2002), essas indústrias progrediram nos últimos anos mais do que os outros setores em dez anos, sendo que três fatores acentuaram a busca da excelência em gestão de projetos nesses setores: fusões, aquisições e legislação, todos associados à competitividade e à necessidade de sobrevivência das empresas.

Alguns estudos recentes apontam para o aumento do índice de sucesso dos projetos. Dentre as razões enumeradas pelo Standish Group International, Inc. (2001) e por Johson ${ }^{3}$, citado por Crawford (2002, p. 8), estão:

- Tendência à utilização de projetos menores e menos complexos, com conseqüente diminuição do custo médio;

- Desenvolvimento de ferramentas de controle de progresso dos projetos e aumento da utilização de processos de gerenciamento;

- Capacitação dos gerentes de projetos, resultando em um melhor gerenciamento dos projetos;

- Uso de estruturas como as constituídas através dos EGPs.

Assim, a implantação do EGP pode ser vista como um meio para obtenção de sucesso em projetos e está relacionada ao surgimento e propagação da disciplina.

\section{O EGP}

A origem do EGP está associada aos departamentos de projetos existentes no final da década de 1950 e início dos anos 1960. O departamento de projetos possuía atuação restrita aos grandes projetos e tinha como principais funções a atualização dos cronogramas e a preparação da documentação do cliente. Geralmente o departamento era associado ao espaço físico que ocupava e atendia a um único cliente (KERZNER, 2002); (KERZNER, 2003).

Atualmente o EGP, também conhecido como Project Management Office (PMO), possui diversas definições, sendo que a maioria delas está associada ao fato de agregar as fontes das melhores práticas de gerenciamento de projetos. Desta forma, o EGP é tido como o responsável por implementar, manter e suprir as necessidades da organização no que se refere a essa disciplina (CRAWFORD, 2002); (ENGLUND et al., 2003); (KERZNER, 2003).

Igualmente diversas são as classificações ou níveis dos EGPs. A classificação proposta por Crawford (2002) e Englund et al. (2003) divide os EGPs em três níveis, que podem existir concomitantemente na organização:

\section{Nível 1 - Escritório de Controle de Projetos}

O Escritório de Controle de Projetos possui como principais funções o desenvolvimento do planejamento do projeto e a emissão de relatórios de progresso. Apresenta foco em um único projeto, porém de grande porte e complexidade. (CRAWFORD, 2002).
Nível 2 - Escritório de Projetos da Unidade de Negócios

O Escritório de Projetos Nível 2 oferece suporte aos projetos da área, de diferentes porte e complexidade. Crawford (2002) destaca como principais funções do EGP a priorização entre os projetos e o gerenciamento de recursos. Entretanto, a integração destes projetos ocorre ao nível da Unidade de Negócios, não atingindo o nível corporativo.

\section{Nível 3 - Escritório Estratégico de Projetos}

As principais atribuições do Escritório de Projetos Nível 3, segundo Crawford (2002), são:

- Selecionar, priorizar e garantir a integração dos projetos que estejam alinhados à estratégia da organização, inclusive no que se refere ao uso de recursos;

- Desenvolver, atualizar e divulgar a metodologia de gerenciamento de projetos, bem como divulgar o conhecimento em gerenciamento de projetos;

- Tornar-se um centro de gestão do conhecimento, através do armazenamento de informações dos projetos na forma de lições aprendidas;

- Validar as estimativas de recursos feitas pelos projetos, baseado nas experiências de projetos anteriores.

\section{Implantação do EGP}

Apesar do conhecimento dos benefícios relacionados ao EGP, implantá-lo apresenta alguns desafios, principalmente por representar uma mudança cultural para a organização e envolver pessoas. Embora disseminar a cultura de gerenciamento de projetos exija tempo, Crawford (2002) sugere que a organização imprima certa velocidade à implantação do EGP, de modo a apresentar os primeiros resultados em seis meses.

Outro fator a ser considerado no processo de implantação do EGP é o seu escopo de atuação, uma vez que a resistência apresenta diferentes níveis conforme novas responsabilidades são incorporadas. As atividades operacionais são facilmente aceitas pela organização, ou seja, apresentam baixo risco, pois implicam em uma pequena mudança de poder e não alteram a cultura organizacional. Como exemplos destas atividades, citam-se o desenvolvimento de metodologia e padrões, os treinamentos e o gerenciamento dos principais interessados. Por sua vez, existem outras atividades cuja implementação apresenta risco moderado, já que podem ocasionar alteração na estrutura de poder e autoridade da organização, como, por exemplo, o planejamento estratégico para o gerenciamento de projetos, a manutenção do histórico de lições aprendidas e os relatórios de desempenho. Por fim, as atividades de alto risco estão relacionadas à existência de grupos de resistência, uma vez que alteram a estrutura de poder e autoridade da organização. Como exemplos destas atividades, podem ser citadas: a comparação das práticas da organização às práticas de outras empre- 
sas, a condução dos processos de priorização e aprovação dos projetos, bem como a auditoria interna de projetos. De forma a obter suporte para o estabelecimento do EGP, devem ser implantadas, primeiramente, as atividades de baixo risco (KERZNER, 2003).

De acordo com Englund et al. (2003), a implantação do EGP deve ser feita em três etapas. Na primeira são criadas as condições para a mudança, e por isso a mesma é crítica para o sucesso do EGP. Englund et al. (2003) sugerem como passos dessa primeira etapa:

1) Evidenciar a importância da mudança e o senso de urgência junto aos membros da organização. Dentre as justificativas para a necessidade da mudança ocorrer nesse momento, podem ser utilizadas as taxas de insucesso em projetos e a comparação das práticas da organização às práticas de outras empresas.

2) Identificar possíveis grupos de resistência e apresentar a estes grupos os benefícios da mudança.

3) Buscar um patrocinador influente e desenvolver coalizões com membros da empresa.

4) Estabelecer quais as contribuições do EGP para atingir a visão do futuro da organização.

5) Elaborar o plano para implantação do EGP e divulgá-lo à organização.
- Segundo os respondentes, a maioria das empresas apresenta nível de maturidade médio, sendo que a pesquisa não definiu previamente um modelo de maturidade para análise;

- Os principais fatores motivadores para a implantação do EGP foram: a necessidade de alinhamento com as melhores práticas de gerenciamento de projetos do mercado, a ausência total ou parcial de controle do portfólio sentida pela gerência executiva e a ausência total ou parcial de metodologia, processos e padrões de gerenciamento;

- Os EGPs geralmente foram implantados acoplados a uma diretoria ou gerência específica, o que faz com que nem todos os projetos da empresa sejam administrados pelo EGP. Geralmente, são administrados os projetos de valor elevado, de alta complexidade ou de inovação;

- A maioria das implantações foi feita sem apoio de consultoria externa e fazendo uso de um projeto-piloto;

- Para a maioria dos respondentes, o grau de envolvimento da alta administração na implementação foi alto;

- A maioria dos respondentes atribui à implementação do EGP ganhos de desempenho dos projetos, dentre outros: melhorias relacionadas à lucratividade, ao cumprimento dos prazos, à adequação ao orçamento, à entrega do escopo previsto, ao grau de satisfação de clientes, da alta diretoria da empresa e das equipes de projeto, além do grau de motivação dos gerentes de projeto.

\section{EGP é realidade em muitas empresas do setor de telecomunicações,} exercendo papel subjacente no processo de crescimento das organizações.

Na segunda etapa, os agentes de mudança implementam a mudança, enquanto na terceira e última etapa é necessário motivar para que a situação pós-mudança seja a nova realidade, ou seja, procura-se "recongelar" a nova situação.

De modo particular, no Brasil a produção científica a respeito do EGP ainda é pequena, principalmente por se tratar de um conceito recente. Alguns indícios do perfil dos EGPs brasileiros são apresentados no trabalho elaborado por Barcaui (2003). Dentre os resultados citados no estudo a respeito das empresas que possuem EGPs ou alguma estrutura similar instalada, e que, portanto, passaram pelo processo de implantação, destacam-se:

- A maioria é composta por empresas multinacionais de grande porte;

- Os principais ramos de atividade das empresas dos respondentes que possuem EGPs ou alguma estrutura similar instalada são TI, Telecomunicações e Engenharia;

- A maioria possui estrutura organizacional predominantemente do tipo matricial;
Ressalva-se, porém, que o estudo apresenta como limitação a abrangência da amostra, não permitindo a generalização das suas conclusões (BARCAUI, 2003).

Outros indícios sobre a condução do processo de implantação do EGP em empresas brasileiras ou instaladas no Brasil são encontrados nos anais de encontros das comunidades de gerenciamento de projetos. Assim, foram identificados estudos de casos descrevendo o processo de implantação dos EGPs de diversas empresas que, embora pertençam a ramos de atuação distintos, apresentaram diversas similaridades, sendo algumas delas resumidas a seguir.

Primeiramente, entre os fatores motivadores para a implantação do EGP nos casos em questão foram citados:

- A demanda por uma metodologia padronizada de gerenciamento de projetos (ANSELMO; MAXIMIANO, 2003);

- A existência de projetos estratégicos (SCHELP, 2003);

- O direcionamento da alta administração (MERKT, 2003); (SCHELP, 2003);

- A tentativa de assegurar a vantagem competitiva (MERKT, 2003).

Adicionalmente, o apoio da alta administração foi apontado como fator crítico de sucesso para a implantação do EGP por Anselmo; Maximiano (2003) e por 
Schelp (2003). Por sua vez, como dificuldades encontradas, destacaram-se a cultura organizacional e a resistência das pessoas no que tange às mudanças organizacionais necessárias (ANSELMO; MAXIMIANO, 2003); (SCHELP, 2003), além da falta de entendimento das atribuições do EGP (SCHELP, 2003).

Finalmente, em alguns dos casos, a implantação do EGP ocorreu concomitantemente à outra iniciativa visando à disseminação da cultura de gerenciamento de projetos (SCHELP, 2003) ou ainda à aplicação de um modelo de maturidade em gerenciamento de projetos (MERKT, 2003). Também foram encontrados casos (SKROBOT; MAYER, 1996); (RABECHINI Jr. et al., 2002) descrevendo a implantação do gerenciamento de projetos sem menção da existência do EGP. Também nesses estudos foi reforçada a importância do papel da alta administração no processo.

\section{ABORDAGEM METODOLÓGICA}

A utilização do estudo de caso como método de pesquisa apresenta como vantagens a manutenção das características principais de eventos da vida real e a garantia da visão holística do problema estudado (YIN, 1994). De acordo com esta referência, três condições devem ser obedecidas para a escolha do estudo de caso como método de pesquisa: as questões de pesquisa devem ser do tipo "como" ou "por que", o pesquisador não deve exercer controle sobre os eventos a serem investigados e o foco da pesquisa deve ser um fenômeno contemporâneo inserido em um contexto da vida real. Para o presente artigo, estas condições foram satisfeitas e assim o estudo de caso foi utilizado como método de pesquisa.

Os dados e informações foram levantados através de entrevistas, nas quais procurou-se identificar as principais dificuldades e os fatores de sucessos encontrados na implantação e consolidação do EGP, considerando o contexto de junção de empresas operadoras de telefonia celular. Uma vez apresentados os resultados, os mesmos foram analisados comparativamente com estudos de casos análogos na forma de artigo, considerando a bibliografia existente sobre gerenciamento de projetos.

Assim, o presente estudo pretende responder à questão da pesquisa: Quais são os fatores que influenciam o processo de consolidação do EGP?

Para essa questão, foram consideradas como hipóteses que os seguintes fatores influenciam o processo de consolidação do EGP:

1) $O$ desenvolvimento das competências em gerenciamento de projetos, de forma aderente às características organizacionais da empresa.

A adoção e o desenvolvimento da metodologia de gerenciamento de projetos carecem de transformações profun- das na cultura organizacional (RABECHINI, 2003). Nas diversas camadas da estrutura da empresa, a saber, indivíduos, equipe e organização, o desenvolvimento de competências em gerenciamento de projetos, visando estabelecer uma cultura voltada para projetos, influencia positivamente no processo de consolidação do conceito de EGP, ao mesmo tempo em que precisa respeitar as características da cultura organizacional da empresa.

2) $\mathbf{O}$ modelo da estrutura organizacional deve ser capaz de absorver as transformações necessárias à condução de projetos estratégicos e complexos.

A estrutura organizacional, em concordância com os modelos propostos pela literatura, a saber, projetizada, matricial e/ou funcional (RAD, 2000), deve ser capaz de absorver as transformações necessárias à condução de projetos estratégicos e complexos.

3) O entendimento do EGP como meio de geração de resultados.

O entendimento do EGP como elemento importante na geração de resultados desejados aos negócios da organização, seja através do melhor desempenho dos projetos, seja pela sua função de suporte ao planejamento estratégico das organizações, influencia o processo de consolidação do EGP.

\section{4) A influência do patrocinador}

No meio profissional é tida como necessária a presença de um forte patrocinador como parte do sucesso para a consolidação do conceito de EGP. Neste trabalho, busca-se ratificar a importância do patrocinador na manutenção da vontade política do processo de consolidação do EGP, principalmente quando as atividades do EGP passam do nível operacional para o nível estratégico, com maior risco para a estrutura de poder da empresa. Helme et al. (2005) apresenta em seu estudo sobre a avaliação do papel do patrocinador no apoio de projetos complexos as seguintes necessidades, dentre outras: habilidade e disposição para conectar os projetos à organização; compatibilidade pessoal com outras pessoas chaves da organização; apropriada "senioridade" e forças dentro da organização.

\section{ESTUDO DE CASO}

Os itens a seguir apresentam o estudo de caso propriamente dito. Inicialmente, em caráter informativo, são apresentadas as informações sobre a empresa e o contexto no qual ela está inserida. Em seguida, apresenta-se o projeto que executou a implantação, o contexto onde a implantação ocorreu e as principais características do EGP. Finalmente apresenta-se como o EGP foi afetado pela junção entre empresas e como o mesmo consolidou-se após esse histórico, sendo o último item o foco deste trabalho acadêmico. 


\section{A empresa}

A empresa estudada atua como Operadora de Telefonia Celular e tem abrangência em todo o território brasileiro. Está entre as maiores do hemisfério sul, tendo resultado da junção de operadoras originalmente pertencentes a dois grupos estrangeiros. Os principais serviços oferecidos pela empresa estão relacionados à transmissão de voz e dados.

Embora esteja em posição de liderança no mercado nacional, desde 2002 a empresa vem enfrentando desafios para manter essa posição. Para vencê-los, uma das estratégias adotadas foi a consolidação dos sistemas de informação, visando comprimir os ciclos para lançamento de novos produtos e serviços, possibilitar o lançamento de campanhas nacionais, melhorar os índices de atendimento ao cliente e reduzir os custos de manutenção e operação de sistemas. Esses objetivos coincidem com as exigências do mercado atual, que acabaram por fazer com que as organizações se voltassem para o gerenciamento de projetos, segundo Crawford (2002).

Quanto à estrutura organizacional, pode-se dizer que, analisada globalmente, a empresa possui estrutura funcional, ou seja, a estrutura de poder está nas colunas. Entretanto, visando atender às exigências de mercado, a empresa vem esboçando ensaios de estruturas matriciais ou projetizadas em áreas específicas, para atender às necessidades de projetos estratégicos e complexos.

\section{Implantação do EGP}

A necessidade de consolidação dos sistemas da empresa surgiu do processo de junção, associado ao cenário caracterizado pela escassez de recursos, pela dificuldade de priorização dos projetos e por falhas, em sua maioria relacionadas aos atrasos e aos produtos entregues sem atender às expectativas dos clientes internos. Assim, a estruturação de um programa de consolidação de TI foi o principal fator motivador para a implantação de um EGP, dando origem ao Projeto de Implantação do EGP para o Programa de Consolidação de Sistemas.

Desde o início, o EGP foi entendido como elemento facilitador e condutor da mudança para a cultura de gerenciamento de projetos. Por isso, a empresa considerou que a implantação do EGP não seria possível sem o desenvolvimento de competências em gerenciamento de projetos e, como no caso apresentado em SCHELP (2003), estabeleceu o Projeto de Formação de Profissionais em Gerenciamento de Projetos. Esse projeto se iniciou antes do Projeto de Implantação do EGP e teve como objetivo disseminar a cultura de gerenciamento de projetos nas áreas da empresa com maior envolvimento em projetos. Para tanto, foram realizados treinamentos formais e aconselhamento em projetos ("mentoração"). Além disso, metade dos colabo- radores participantes do programa foi certificada como profissionais de gerenciamento de projetos (PMP Project Management Professional ${ }^{4}$ ).

Ambos os projetos, Formação de Profissionais em Gerenciamento de Projetos e Implantação do EGP para o Programa de Consolidação de Sistemas, foram formalmente vinculados à estratégia da empresa, garantindo assim o apoio formal da alta administração.

\section{Projeto de Implantação do EGP para o Programa de Consolidação de Sistemas}

A implantação do EGP foi tratada como um projeto, sendo então o primeiro a utilizar a metodologia proposta, ainda em elaboração. Inicialmente foram focadas pelo EGP as atividades operacionais, como forma de garantir a aceitação pela estrutura de poder da empresa, tornando o EGP um aliado ao cumprimento dos objetivos dos projetos conduzidos por essa estrutura.

As principais dificuldades encontradas na implantação referem-se à mudança cultural que o EGP representava e à resistência das pessoas devido à alteração da estrutura de poder. Os principais riscos identificados pela empresa ao longo do projeto de implantação e as respectivas estratégias de resposta foram:

- Ameaça à credibilidade do EGP: sendo o EGP responsável por informar o status dos projetos sob a liderança das diretorias de TI, era imprescindível que estes diretores confiassem no EGP e o tivessem como aliado. Para tanto, foi inserido o papel do Facilitador, uma pessoa de confiança dos diretores, normalmente um gerente funcional, que participava dos projetos ao lado dos gerentes e "dividindo" o papel de patrocinador com o Diretor de TI. O EGP tinha uma relação muito estreita com esses Facilitadores, informando-os, em primeira instância, sobre os eventuais problemas, para que tivessem tempo de agir, antes da publicação do status final.

- Dificuldade em encontrar no mercado profissionais com o perfil adequado ao EGP: como ainda era recente a explosão do gerenciamento de projetos, havia poucos profissionais disponíveis que conheciam as funções de um EGP e alguma metodologia em gerenciamento de projetos. A solução encontrada foi a contratação de um profissional certificado em gerenciamento de projetos e dos serviços de consultoria de terceiros com experiência anterior em EGPs. Assim, a equipe do EGP foi formada por esses profissionais, associados a outros com conhecimento da empresa, porém menos experientes em gerenciamento de projetos. Visando eliminar a eventual dependência da consultoria na fase pós-implantação, durante a fase piloto pesquisaram-se em outras áreas colaboradores dispostos a integrar a equipe. Deste modo, a participação da consultoria reduzia-se à medida que novos integrantes ingressavam na equipe do EGP. 
- Dificuldade para formalizar a estrutura no organograma da empresa: tendo em vista a iminente unificação com outro grupo empresarial, não foi possível a formalização de uma nova estrutura, já que uma alteração muito maior iria acontecer. Sendo assim, buscou-se fortalecer as funções e responsabilidades do EGP, procurando-se evidenciar a importância dessas atividades para a obtenção de resultados nos principais projetos da empresa. Assim, ao mesmo tempo em que o EGP atuava diretamente comprometido com o sucesso dos projetos, possuía atuação focada na organização e empenhava-se na aplicação da metodologia como ferramenta para direcionar a equipe rumo aos objetivos.

\section{Caracterização do EGP}

O EGP de TI entrou em operação ao término do seu projeto de implantação, com o portfólio restrito aos projetos do Plano de Consolidação de Sistemas.

Entre as principais funções do EGP implantado citam-se:

- Desenvolver e divulgar a metodologia de gerenciamento de projetos, buscando identificar suas melhores práticas;

- Escolher e implantar as ferramentas definitivas de gestão de projetos, uma vez que durante a fase inicial do projeto foram implantadas somente as ferramentas básicas, enquanto as definitivas aguardavam a consolidação da metodologia;

- Criar e manter base de dados de gerenciamento dos projetos;

- Gerenciar o Plano de Comunicação, divulgando informações relevantes sobre os projetos e sensibilizando os patrocinadores para os problemas em que precisavam atuar junto ao gerente de projeto ou ao facilitador;

- Desenvolver a cultura de gerenciamento de projetos na organização;

- Garantir o alinhamento dos projetos à estratégia da organização;

- Antecipar os potenciais problemas, para que os responsáveis de cada projeto pudessem atuar no sentido de cumprir os objetivos do projeto.

Da organização interna do EGP, destaca-se que a mesma possuía um único líder e estava subordinada diretamente ao seu patrocinador. Outro papel de destaque no organograma do EGP era o de Coordenador de Programas, responsável por atuar junto aos gerentes de projetos, oferecendo suporte na utilização da metodologia, responsabilizando-se pela atualização dos cronogramas de projetos e eventualmente atuando como mentores. Por sua vez, os gerentes de projetos não faziam parte da organização interna do EGP, o que trazia algumas vantagens, podendo-se destacar:
- O EGP tornava-se mais ágil, capaz de atuar em diversos projetos, sem ter que aumentar a equipe de forma excessiva;

- A disseminação da cultura de gerenciamento de projetos era facilitada, pois como o gerente de projetos estava nas áreas funcionais e, na maioria das vezes, era um participante do Programa de Formação de Profissionais em Gerenciamento de Projetos, exercia papel fundamental na formação dos demais membros da equipe funcional;

- A estrutura de poder foi poupada, uma vez que os gerentes de projetos estavam subordinados às áreas funcionais das Diretorias de TI, estimulando a liderança e participação do diretor e seus gerentes funcionais.

Complementarmente, para fazer com que a organização como um todo reconhecesse a função do EGP, mesmo sem estar formalmente no organograma da empresa, foi estabelecida uma sigla de fácil utilização, além de um logotipo, utilizado em todos os documentos e e-mails emitidos pela equipe do EGP.
Impactos da junção das empresas na operação do EGP

Seis meses após a implantação do EGP, a empresa passou pelo já esperado processo de unificação com outro grupo empresarial. O EGP, que já estava em funcionamento, continuou não sendo formalizado na nova estrutura organizacional. Primeiramente pela dificuldade de absorção de uma estrutura formal de EGP pela nova empresa que estava sendo formada, associada à perda do principal patrocinador do EGP, desligado da empresa, e ao clima de mudança presente em todas as áreas. Apesar disso, a mudança cultural estava consolidada, principalmente pela conclusão do Projeto de Formação de Profissionais em Gerenciamento de Projetos, pela divulgação da metodologia e pelos resultados que vinham sendo obtidos em projetos com a implantação do EGP. Assim, como as funções do EGP foram reconhecidas como essenciais, as lideranças que passaram a se envolver com a unificação da nova empresa buscaram garantir a contínua disseminação destas práticas de gerenciamento. Para tanto, distribuíram a equipe do EGP pelas novas diretorias de TI, especificamente nos projetos de consolidação iniciados logo após a unificação. Deste modo, existiria em cada projeto ao menos um profissional aplicando a metodologia e fornecendo suporte ao gerente de projetos no 
planejamento e controle do mesmo. Isso se deu porque essas lideranças estavam cientes da necessidade do gerenciamento de projetos para obtenção do sucesso nos projetos do programa de consolidação, que se tornaram ainda mais complexos após a junção das empresas. Com isso, acabaram por suportar o reinício da implantação do EGP, desta vez com as características da nova empresa.

Também nesta época foi introduzido o conceito de time principal, também conhecido como core-team. Tratava-se de equipes multidisciplinares cujos membros possuíam as competências necessárias ao projeto, ao mesmo tempo em que representavam as principais áreas envolvidas. Essa estrutura foi proposta visando garantir a distribuição de responsabilidades, necessária no novo ambiente dos projetos que começara a surgir, pois proporcionava a participação formal de diferentes áreas funcionais, ao mesmo tempo em que diminuía a quantidade de canais de comunicação entre a equipe e o gerente do projeto. Além disso, essa forma de organização das equipes possibilitou a disseminação mais rápida da nova forma de trabalho por projetos e a criação de um comportamento voltado para o gerenciamento de projetos e conseqüente cumprimento dos seus objetivos.

Uma vez que os objetivos dos projetos de consolidação eram ousados, principalmente na gestão dos prazos, o uso da metodologia de gerenciamento foi um diferencial, uma vez que possibilitava a atuação focada nos objetivos, sendo os resultados percebidos ao longo de todas as fases e gerando confiança das áreas usuárias. Após um ano, foram iniciadas as implantações dos sistemas, todas bem sucedidas, sem impactos às áreas operacionais ou aos clientes finais.

\section{Consolidação do EGP}

Após a implantação dos projetos de consolidação acima mencionados, novos projetos também de consolidação foram incluídos no programa ${ }^{5}$. Tais projetos eram ainda mais complexos e abrangentes, razão pela qual passaram a ser tratados como projetos estruturantes, e não mais como projetos de tecnologia, à medida que pressupunham, na consolidação das plataformas, a alteração da estrutura de processos, produtos e serviços. A existência do EGP, cuja atuação passou a estar além das fronteiras da área funcional de Tecnologia, foi apontada pelos patrocinadores e pelos gerentes desses projetos como garantia de sucesso. Deste modo, a formalização do EGP deu-se principalmente pela existência de projetos tidos como estratégicos, sendo esse um dos fatores citados por Kerzner (2002) como motivadores da busca da maturidade em gerenciamento de projetos.

Nessa época, a estrutura organizacional da empresa, embora ainda na sua maior parte funcional, foi flexibilizada para adequar-se à nova realidade, sendo formaliza- das duas estruturas de gerenciamento de projetos que permanecem na empresa até a ocasião da realização deste estudo de caso. A primeira é subordinada à área funcional de Tecnologia e com atuação nos projetos desta área. É responsável pela manutenção da metodologia e das ferramentas de gerenciamento de projetos, além de atuar como prestadora de serviços para a segunda estrutura, subordinada a uma das Vice-Presidências Operacionais. Esta vice-presidência é patrocinadora da maioria dos projetos estruturantes e atua especificamente no cumprimento dos objetivos do Programa de Consolidação de Sistemas. No seu âmbito, é uma diretoria de estrutura matricial, tendo nas colunas os líderes dos projetos e, nas linhas, gerentes de função que atuam transversalmente em todos os projetos, desempenhando as funções: Tecnologia, Processos, Implantação e EGP. Essa segunda estrutura está condicionada à duração do Programa, estando os profissionais temporariamente alocados a ela, podendo retornar às suas áreas de origem ao final de cada projeto.

Dentre as principais funções exercidas pelo EGP após a Consolidação citam-se:

- Garantir a aplicação da metodologia de gerenciamento de projetos;

- Integrar os planos dos projetos dentro do próprio Programa e aos outros projetos de tecnologia;

- Garantir o alinhamento dos projetos à estratégia da organização;

- Atuar de forma preventiva, no sentido de preservar o plano de cada projeto e do programa como um todo;

- Ressaltar os pontos de risco de cada projeto aos líderes de projetos, aos patrocinadores e aos demais interessados, auxiliando na definição e aplicação de ações preventivas ou corretivas, no sentido de preservar o plano.

Um fator crítico para o sucesso desta estrutura foi o fato da mesma ser considerada uma evolução natural de todo o processo de implantação do EGP, podendo contar com todas as ações anteriores de estruturação para implantação de uma nova cultura.

A principal dificuldade enfrentada nesta fase está relacionada à forma de trabalho em uma estrutura matricial, onde cada profissional deve aprender a trabalhar com diversos níveis de subordinação e atuar com influência na estrutura funcional para atingir os objetivos do projeto, além de garantir a incorporação das entregas dos produtos dos projetos aos processos operacionais da estrutura funcional.

Dentre os resultados atribuídos pela empresa, total ou parcialmente, à implantação do EGP encontram-se:

- Crescimento da empresa e atendimento da exigência de mercado em relação ao prazo de lançamento dos novos produtos;

- Implantação da metodologia de gerenciamento de proje- 
tos, com conseqüente obtenção de sucesso nos mesmos, ou seja, projetos implantados sem causar impacto nas operações da companhia ou ao cliente final.

- Mudança de cultura, envolvendo todas as áreas de negócio.

\section{RESULTADOS OBTIDOS}

Com relação às hipóteses formuladas sobre os fatores que influenciam o processo de consolidação do EGP, cada fator foi analisado conforme a seguir:

1) $O$ desenvolvimento das competências em gerenciamento de projetos, de forma aderente às características organizacionais da empresa.

No caso analisado observou-se que o EGP respeitou a cultura da empresa em dois momentos:

- Na implantação, quando a junção das empresas era iminente e não caberia uma proposta de alteração do organograma. Neste momento, a alternativa adotada foi o investimento na formação dos profissionais e na consolidação da metodologia.

- Após a junção das empresas, quando se esperava a formalização e a mesma não ocorreu. Como alternativa, investiu-se na aplicação da metodologia e do modelo operacional já estabelecido em projetos estratégicos e complexos, evidenciando o valor do EGP nesses projetos.

Assim, ter como base a cultura da organização e a realização de treinamentos extensivos, durante a implantação do EGP, foram considerados fatores críticos de sucesso, coincidindo com os fatores apresentados por Kerzner (2002). Sendo capaz de se adaptar, o EGP mostrou seu valor e conquistou a formalização em uma estrutura especificamente criada para gerenciar os maiores e mais complexos projetos da empresa. Isso foi viabilizado pelo fato de o EGP ter se apoiado em pilares que promoviam a disseminação da cultura e da metodologia de gerenciamento de projetos, preparando a organização para a sua formalização, enquanto apresentando bons resultados e incrementando a demanda pelas funções de um EGP. Estes pilares foram apresentados no estudo de caso e estão resumidos a seguir:

- A equipe do EGP era pequena, ágil e capaz de atuar em diversos projetos simultaneamente, através do papel do Coordenador de Programas;

- A disseminação da cultura de gerenciamento de projetos foi facilitada pelos gerentes de projetos que haviam participado do Programa de Formação e que foram mantidos nas áreas funcionais, enquanto ajudados pelos Coordenadores de Programa.

2) O modelo da estrutura organizacional deve ser capaz de absorver as transformações necessárias à condução

\section{de projetos estratégicos e complexos.}

Neste estudo de caso, foi evidenciada a predisposição da empresa em adaptar sua organização formal à forma de trabalho em projetos. Mesmo antes de alterá-la formalmente, foi possível introduzir conceitos e formas de trabalho que serviram de aprendizado para a posterior formalização. Uma das principais ferramentas utilizadas pelo EGP para ganhar flexibilidade e permeabilidade de suas funções na organização foi o conceito de time principal. Utilizando este conceito, o EGP garantiu a formalidade aos projetos e mostrou à organização a necessidade de se trabalhar com times multidisciplinares, capazes de agregar as competências necessárias aos projetos.

Embora a estrutura flexível tenha permitido a consolidação do EGP, a mesma trouxe novas dificuldades, como os diversos níveis de subordinação, a atuação com influência na estrutura funcional para atingir os objetivos do projeto e a garantia das entregas dos produtos dos projetos a esta estrutura funcional.

Considerando os três níveis de EGP apresentados por Crawford (2002), constatou-se que as funções do EGP, no caso estudado, estão distribuídas, principalmente, entre os níveis 1 e 3. Neste caso, o nível 1 (Escritório de Controle de Projetos) refere-se aos EGPs que atuam com foco em cada um dos projetos estruturantes, enquanto o nível 3 (Escritório Estratégico de Projetos) coordena os EGPs de nível 1 dos projetos estruturantes e faz o relacionamento com a estratégia da organização. O nível 2 está presente na estrutura de gerenciamento de projetos formalizada dentro da unidade de negócio de Tecnologia, que cuida de funções como metodologia e ferramentas de suporte.

3) $O$ entendimento do EGP como meio de geração de resultados.

Dentre as diversas razões mencionadas por Kerzner (2002) pelas quais as organizações decidem pela implantação das práticas de gerenciamento de projetos, foi possível observar neste caso específico a presença de duas delas: a existência de projetos estratégicos e o maior comprometimento dos gerentes executivos.

Uma vez que a empresa em questão estava inserida em um ambiente dinâmico, com recursos escassos e metas agressivas, o EGP exerceu papel fundamental escolhendo ferramentas úteis para a equipe e para cada um dos projetos e relacionadas ao cumprimento de seus objetivos.

Quanto à implantação do EGP, Crawford (2002) sugere como fator de sucesso que a organização imprima certa velocidade à mesma, de modo a apresentar os primeiros resultados em seis meses. No caso apresentado, esse fator foi verificado, pois quatro meses após o início de sua estruturação e dois meses após sua implantação o EGP já apresentava resultado em projetos. 


\section{4) A influência do patrocinador.}

No caso apresentado, o EGP começou atuando em atividades operacionais que não trouxessem riscos à estrutura de poder e assim pôde se estabelecer como um aliado ao cumprimento dos objetivos dos projetos conduzidos por esta própria estrutura. Somente depois disto, começou a atuar em atividades estratégicas, conforme demanda da própria empresa, o que, aliado ao apoio do patrocinador forte, facilitou a atuação do EGP no nível 3.

Ao longo de todo o histórico deste EGP foi possível perceber a importância de um patrocinador. No início o patrocinador era um único executivo, aos poucos, através de todas as estratégias de disseminação da cultura, foi se transformando em vários executivos das principais áreas de negócio, que passaram a apoiar o EGP e suas funções, facilitando, principalmente as funções relacionadas ao planejamento e controle dos projetos.

A importância do apoio executivo também ficou evidente quando o mesmo não esteve presente, principalmente no momento de junção das empresas, quando a demarcação de poder era fator decisivo para os executivos e acabou dificultando a formalização do EGP, que foi deixado de lado e perdeu força. Somente no fim dessa fase o EGP obteve apoio executivo e voltou a ser entendido como fator fundamental para a execução de projetos estratégicos.

Os resultados obtidos se tornam indícios de que as hipóteses inicialmente formuladas são válidas para o caso estudado e, considerando que foram observadas em estudos de caso análogos publicados na forma de artigos, podem servir de exemplo e nortear situações similares, desde que preservadas as características únicas de cada empresa.

\section{CONSIDERAC̣ÕES FINAIS}

O desenvolvimento do presente trabalho foi motivado pelo envolvimento dos autores com as práticas de gerenciamento de projetos e pela percepção dos mesmos em relação à ampla divulgação, no ambiente corporativo, do conceito de projeto, enquanto forma de traduzir a estratégia da empresa, de conduzi-la rumo aos seus objetivos e, em última instância, transformá-la.

De modo particular, o interesse pelo caso em questão deuse principalmente pelo contexto de junção de grupos empresariais, onde se esperava que o caráter formal do gerenciamento de projetos facilitasse a condução de projetos de mudança de cultura e proposição de novas estruturas de trabalho. Tal fato foi verificado no caso analisado e procurouse evidenciar na sua descrição. Assim, ao mesmo tempo em que o EGP estudado atuou como agente de transição para projetos de consolidação de TI, também gerou a necessidade de adaptação da estrutura organizacional para uma estrutura mais flexível e capaz de absorver a forma de trabalho em equipes multidisciplinares. No entendimento dos autores, a formalização desta estrutura, mesmo que temporária (devido à própria natureza temporária dos projetos), denotou a importância que a empresa estudada dá ao EGP.

Além disso, diante dos estudos de caso e referências bibliográficas analisadas, foi possível entender que não existe uma forma única de implantação de EGPs, sendo que cada caso depende da cultura organizacional e do contexto no qual a empresa estiver inserida.

Adicionalmente, destaca-se que no caso analisado a escolha da estratégia de implantação do EGP adequou-se à maturidade da empresa: em cada momento distinto o EGP apresentou características diferentes. Porém, verificou-se no caso que a aceitação plena da metodologia somente foi verificada a partir da apresentação de resultados práticos e mensuráveis.

Finalmente, o presente trabalho procurou contribuir cientificamente, à medida que foram identificados os fatores que influenciaram o processo de consolidação do EGP na empresa estudada e que podem ser considerados indícios para casos similares. Porém, como restrição do método de pesquisa utilizado, tem-se a impossibilidade da generalização das suas conclusões. Tal generalização seria possível a partir da análise de uma amostra significativa dos EGPs de empresas brasileiras, podendo esta vir a ser objeto de novos estudos.

\section{Artigo recebido em 11/06/2005 \\ Aprovado para publicação em 05/12/2005}

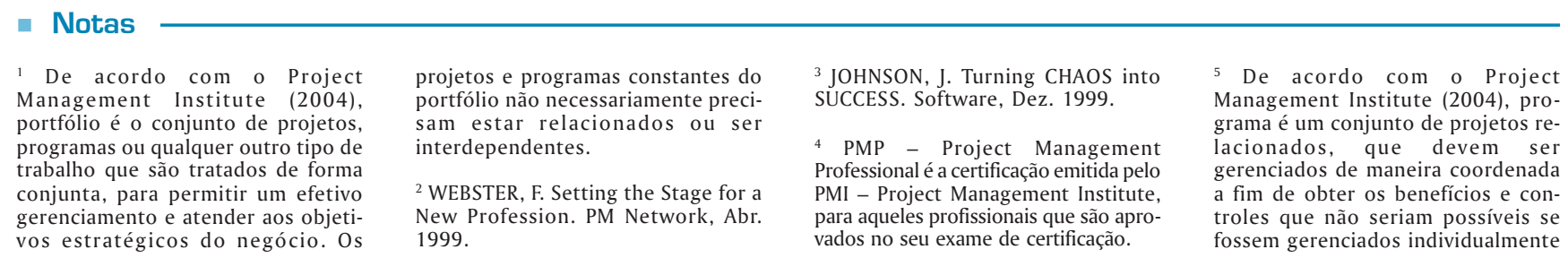


ANSELMO, J. L.; MAXIMIANO, A. C. A. Escritório de Gerenciamento de Projetos: Um Estudo de Caso. In: CONGRESSO IBERO-AMERICANO DE GERÊNCIA DE PROJETOS, 4., São Paulo: Rio de Janeiro, 2003. Anais eletrônicos. São Paulo; Rio de Janeiro: Project Management Institute, 2003. Disponível em: < http://www.pmisp.org.br/ congresso/ $>$. Acesso em: 3 maio 2005.

BARCAUI, A. B. Perfil dos Escritórios de Projetos em organizações atuantes no Brasil. 2003. 151. Dissertação (Mestrado) - Universidade Federal Fluminense. Niterói, 2003

CAMPANÁRIO, M. A.; SILVA, M. M.; ROVAI, R. L. Gestão da inovação no setor de telecomunicações: Inovação Tecnológica e Políticas Públicas em Telecomunicações no Brasil. São Paulo: SBD/FEA/USP, 2004

CRAWFORD, J. K. The Strategic Project Office: A Guide to Improving Organizational Performance. New York: Marcel Dekker Inc, 2002.

ENGLUND, R. L.; GRAHAM, R. J.; DINSMORE, P. C. Creating the Project Office: A Manager's Guide to Leading Organizational Change. San Francisco: John Wiley \& Sons, Inc., 2003.
HELME, J.; REMINGTON, K. Effective Project Sponsorship: An evaluation of the role of the executive sponsor in complex infrastructure projects by senior project managers. Project Management Journal, v. 36, n. 3, p. 51, 2005.

KERZNER, H. Gestão de Projetos: as melhores práticas. Trad. Marco Antonio Viana Borges, Marcelo Klippel e Gustavo Severo de Borba. Porto Alegre: Bookman, 2002.

KERZNER, H. Strategic Planning for a Project Office. Project Management Journal, v. 34, n. 2, p.13-25,2003.

MERKT, M.; SANTOS, J.A.; PARIS, W. Estratégia e mudança organizacional: introdução do gerenciamento de projetos em uma organização nãoprojetizada. In: CONGRESSO IBEROAMERICANO DE GERÊNCIA DE PROJETOS, 4., São Paulo; Rio de Janeiro, 2003. Anais eletrônicos. São Paulo; Rio de Janeiro: Project Management Institute, 2003. Disponível em: $<$ http://www.pmisp.org.br/congresso/ $>$. Acesso em: 3 maio 2005.

PROJECT MANAGEMENT INSTITUTE. A guide to the project management body of knowledge (PMBOK Guide) Third Edition. Newtown Square, PA: Project Management Institute Inc. 2004.
RABECHINI JR., R.; CARVALHO, M. M.; LAURINDO, F. J. B. Fatores críticos para implementação de gerenciamento por projetos: o caso de uma organização de pesquisa. Revista Produção, v. 12, n. 2, p.28-41, 2002

RABECHINI JR, R. O Gerente de Projetos na Empresa. São Paulo: Atlas, 2003

RAD, P. F., Establishing an organizational project office. AACE International Transactions, ABI/ INFORM Global, p. P13A, 2000.

RAD, P. F. Is your organization a candidate for project management office (PMO)? AACE International Transactions. ABI/INFORM Global, p. PM71, 2001.

SCHELP, M. X. Implantação de Escritórios de Gerenciamento de Projetos - Estudo de Caso em uma empresa do setor de autopeças. In: CONGRESSO IBERO-AMERICANO DE GERÊNCIA DE PROJETOS, 4., São Paulo; Rio de Janeiro, 2003. Anais eletrônicos. São Paulo; Rio de Janeiro: Project Management Institute, 2003. Disponível em: < http://www.pmisp.org.br/ congresso/ $>$. Acesso em: 3 maio 2005.
SKROBOT, L.C.; MAYER, S. Sistema de Gestão de Projetos TECPAR: 1,5 ano de experiência. In: Simpósio de Gestão da Inovação Tecnológica, 19., São Paulo, 1996. Anais / Organizado por Roberto Sbragia, Jacques Marcovith, Eduardo Vasconcellos. São Paulo: USP/PGT/FIA PACTo, 1996. p. 1517-1528.

TELECO. Portal de informações em telecomunicações. Disponível em: <: ht t p://www.teleco.com.br/ ncel1.asp >. Acesso em: 22 maio 2005.

THE STANDISH GROUP INTERNATIONAL, INC. West Yarmouth, 2001. Extreme CHAOS. Disponível em: $<$ http://www.standishgroup.com/ sample_research/PDFpages/ extreme chaos.pdf $>$. Acesso em: 22 maio $20 \overline{0} 5$.

THE STANDISH GROUP INTERNATIONAL, INC. West Yarmouth, 2004. 2004 Third Quarter Research Report. Disponível em $<$ http://standishgroup.com/ sample_research/PDFpages/q3 spotlight.pdf $>$. Acesso em: 22 maio 2005.

YIN, R. K. Case study research: design and methods. 2. ed. Thousands: Sage Publications, 1994.

\section{- Sobre os autores}

\section{Andréia Pereira Martins}

Pesquisadora do Programa de Pós-Graduação - ênfase em Gestão de Projetos

Escola Politécnica da Universidade de São Paulo - Departamento de Engenharia Naval e Oceânica

Endereço: Av. Professor Mello Moraes, 2231 - CEP 05508-030 - São Paulo - SP - Brasil

Telefone/fax: 5511 3091-5350 r. 254 - E-mail: andreia.martins@ poli.usp.br

\section{Marcelo Ramos Martins}

Professor Dr.

Escola Politécnica da Universidade de São Paulo - Departamento de Engenharia Naval e Oceânica

Endereço: Av. Professor Mello Moraes, 2231 - CEP 05508-030 - São Paulo - SP - Brasil

Telefone/fax: 5511 3091-5350 r. 254 - E-mail: mrmartin@usp.br

\section{Marcia Moreira Martins Pereira}

Pesquisadora do Programa de Pós-Graduação - ênfase em Gestão de Projetos

Escola Politécnica da Universidade de São Paulo - Departamento de Engenharia Naval e Oceânica

Endereço: Av. Professor Mello Moraes, 2231 - CEP 05508-030 - São Paulo - SP - Brasil

Telefone/fax: $55113091-5350$ r. 254 - E-mail: marcia.martins@poli.usp.br

\section{Vergílio Antonio Martins}

Pesquisador do Programa de Pós-Graduação - ênfase em Gestão de Projetos

Escola Politécnica da Universidade de São Paulo - Departamento de Engenharia Naval e Oceânica

Endereço: Av. Professor Mello Moraes, 2231 - CEP 05508-030 - São Paulo - SP - Brasil

Telefone/fax: $55113091-5350$ r. 254 - E-mail: vergilio.martins@ poli.usp.br 